Artigos

\title{
A luta pela identidade: uma análise de "Cara Gente Branca"1 por meio da noç̃o de interseccionalidade de Patrícia Hill Collins
}

\author{
Carlos A. Gadea² \\ Suélen Pinheiro Freire Acosta ${ }^{3}$
}

Resumo: O presente artigo traz uma reflexão sobre as denominadas "lutas identitárias" contemporâneas por meio da perspectiva interseccional entre as noções de raça, classe e gênero, proposta pela socióloga norte-americana Patrícia Hill Collins. Valendo-se de uma análise do primeiro capítulo da série "Cara Gente Branca”, exibida pelo serviço de streaming Netflix, o objetivo é analisar as diferentes situações de opressão vividas pelos protagonistas. A reflexão proposta está alinhada a uma perspectiva de análise sociocultural que assume a interseção de diferentes âmbitos da vida social como constitutiva às diversas identificações que os indivíduos passam a experimentar como produto da própria fragmentação dos conflitos culturais atuais.

Palavras-chave: Cara gente branca; interseccionalidade; gênero; raça; classe.

\footnotetext{
1 "Cara Gente Branca" ("Dear White People", no original em inglês) é uma série de TV americana baseada no filme de 2014 do mesmo nome. Em 2017, faz sua estreia pelo serviço streaming Netflix, resultando em críticas interessantes em torno ao racismo na vida universitária nos Estados Unidos. Série de 10 capítulos com 30 minutos de duração, aproximados, em cada um.

2 Programa de Pós-Graduação em Ciências Sociais da Universidade do Vale do Rio dos Sinos (Unisinos) Bolsista de Produtividade $1 \mathrm{C}$ do CNPq - São Leopoldo - Brasil - cgadea@unisinos.br

3 Universidade do Vale do Rio dos Sinos (Unisinos/ CAPES PROSUC) - São Leopoldo - Brasil - suelenpfacosta@gmail.com
} 


\title{
The fight for identity: an analysis of "Dear White People" through Patrícia Hill Collins's notion of intersectionality
}

\begin{abstract}
This paper presents a reflection on the so-called contemporary "identity struggles" through the intersectional perspective between the notions of race, class and gender proposed by the american sociologist Patricia Hill Collins. Using an analysis of the first chapter of the series "Dear white people", shown by the Netflix streaming service, the objective is to analyze the different situations of oppression experienced by the protagonists. The proposed reflection is aligned in a perspective of socio-cultural analysis that assumes the intersection of different spheres of social life as constitutive to the various identifications that individuals begin to experience as a product of the fragmentation of current cultural conflicts.
\end{abstract}

Keywords: Dear white people; intersectionality; gender; race; class.

\section{Introducç̃o}

Em abril de 2017, no serviço streaming Netflix, fez a sua estreia a interessante série "Cara Gente Branca" (Dear White People, no título original em inglês). Baseada no longa-metragem do mesmo nome, lançado em 2014 e premiado no Festival de Cinema de Sundae, a série obteve, de imediato, um impacto social e midiático importantes, especialmente entre aquelas pessoas "brancas" que consideraram o formato e a temática bastante ofensivos. Poucos dias após a sua estreia, inclusive, grupos que se sentiram ofendidos manifestaram, por meio de seus perfis nas redes sociais, que iriam cancelar a sua assinatura de Netflix, atitude que demonstraria o significativo grau de desconforto suscitado pela série4.

Ambientada na Universidade fictícia de Winchester, "Cara Gente Branca" aborda, fundamentalmente, as relações raciais e o racismo existentes no ambiente universitário nos Estados Unidos, temática que será central já no começo da série, no seu primeiro capítulo5, objeto das análises deste trabalho. No entanto, importa destacar que outros "sistemas de opressão" social também se tornam sobressalentes, e igualmente dignos de reflexão, claramente ressaltados

4 Ver "Após sofrer boicote nos Estados Unidos, série Cara Gente Branca chega à Netflix", IN: Diário de Pernambuco, 28/04/2017. Disponível em: <https://www.diariodepernambuco.com.br/app/noticia/viver/2017/04/28/internas_viver,701595/apos-sofrer-boicote-nos-estados-unidos-serie-cara-gente-branca-chega.shtml>. Acesso em: 13 set. 2019.

5 No primeiro capítulo, a protagonista Samantha White, locutora da rádio universitária, lidera um protesto contra a festa "blackface" no campus, mas uma série de situações da sua vida cotidiana leva a questionar a sua posição como ativista pela causa política negra. 
em correlação com aquele derivado da composição racial da sociedade e o eventual racismo. Trata-se, aqui, de uma observação que sugere refletir acerca dos diversos mecanismos sociais de exclusão, opressão e, obviamente, de resistência em torno a lutas identitárias que não se podem considerar unívocas ou centralizadas em uma única fonte de expressão.

A série se vale de uma vertiginosa narrativa, carregada de um particular estilo humorístico, de ironias constantes e provocações a cada momento. Contado com base no ponto de vista de cinco personagens principais, o acontecimento central desse primeiro capítulo é a realização de uma festa de Halloween, para a qual os estudantes seriam convidados a "fantasiarem-se de negros". Com a presença de muitos estudantes "brancos" usando acessórios ligados aos estereótipos associados à cultura negra e à chamada Blak face, a festa (e seus desdobramentos, como a ressaca) se constituiria no centro da discussão. Nela, a figura principal, Sam (Samantha Whyte, interpretada por Logan Browning), terá grande importância para os interesses da reflexão que aqui trazemos.

Sam é estudante do terceiro ano do Curso de Estudos Audiovisuais, uma declarada anarquista engajada nas lutas antirracistas. Ela, fundamentalmente, é a apresentadora do programa "Cara Gente Branca", na rádio comunitária estudantil, tendo uma série de seguidores na internet, na qual produz e publica diversos conteúdos ligados à causa racial. O notável é que o conteúdo produzido por Sam em seu programa causa um duplo efeito: por um lado, de identificação entre seus colegas negros da universidade, e, por outro, de grande rechaço, especialmente entre os colegas brancos. Contudo, a série não se furta em demonstrar as disputas e conflitos que ocorrem ao interior da universidade, mostrando, também, as desavenças existentes, inclusive, entre os coletivos negros que se formam na universidade.

Mas, Sam não unicamente estaria imersa em relações sociais que a levariam a experimentar a sua negritude sem estar ligada, muito estreitamente, às outras dimensões de opressão e exclusão da vida cotidiana. Sam também era uma mulher jovem, uma mulher jovem e negra que chegaria à universidade com o esforço típico daqueles que, inclusive, advinham de bairros pobres da cidade. Sam era mais do que uma ativista pela causa racial. Por isso, torna-se importante refletir sobre as denominadas lutas identitárias na atualidade, atentando para a complexidade que representa assumir a intersecção social de atributos sobre as diversas identificações que os indivíduos passam a experimentar como produto da própria fragmentação dos conflitos socioculturais. Assim, por meio da perspectiva interseccional entre as categorias de raça, classe e gênero, proposta pela socióloga Patrícia Hill Collins (2015; 2016; 2017), busca-se analisar as diferentes 
situações de opressão vividas por Sam nesse primeiro capítulo da série "Cara Gente Branca”. Para tal, serão considerados, como principais acontecimentos de análise, o próprio ambiente universitário, a festa de Halloween (com todas suas repercussões), o programa de rádio apresentado por Sam e, de maneira importante, sua relação amorosa estável com um colega branco.

\section{A Interseccionalidade em Patrícia Hill Collins}

Com o objetivo de analisar os sistemas de opressão construídos socialmente na interligação entre raça, classe e gênero, a socióloga norte americana Patrícia Hill Collins se converteu em uma das principais referências a utilizar e a desenvolver a noção de interseccionalidade. Por meio dessa abordagem, raça, classe e gênero são categorias enquanto se encontram interligadas nas experiências vividas por todos os indivíduos, variando em sua forma conforme as "lógicas situacionais" (Thomas, 2005 [1923]) e necessidades práticas exigidas. Por exemplo, já as contemporâneas perspectivas analíticas construcionistas, conforme Pisciteli (2006: 266), propõem

oferecer ferramentas analíticas para apreender a articulação de múltiplas diferenças e desigualdades. É importante destacar que já não se trata da diferença sexual, nem da relação entre gênero e raça ou gênero e sexualidade, mas da diferença, em sentido amplo para dar cabida às interações entre possíveis diferenças presentes em contextos específicos.

Nesse sentido, a abordagem interseccional se diferencia de análises baseadas no tradicional pensamento por dicotomias, na medida em que um indivíduo é capaz de vivenciar diversas relações de opressão e, estas, em estreita relação na sua apresentação social posterior.

Pensar por dicotomias a realidade social é, para a socióloga Patrícia Hill Collins, uma tarefa ineficiente e equivocada, passível de erros de diagnóstico quando nos confrontamos à diversidade de mecanismos de opressão e exclusão. Este pensamento não parece dar conta dos arranjos pessoais e sociais de marcadores identitários. Conforme Collins (2015), enquanto este método de análise pode ser entendido com base na metáfora "ou/ou", na construção das identidades cabe muito mais a metáfora "e/ambos", embarcando na ideia de que, não necessariamente, a constituição das identidades se baseia em anular outros marcadores identitários surgidos de algum outro tipo de relação social. O que está afirmando Collins é muito semelhante a uma das sentenças analíticas mais importantes de Stuart Hall (2000) desde os chamados Estudos Culturais: que, 
na contemporaneidade, cada grupo humano adscrito a alguma identificação sociocultural sempre está desafiando a concepção "binária da diferença". Tal qual Laclau e Mouffe (1987) mencionaram, em cada relação social específica se assumem "posições de sujeito"; ou seja, a relação social mesma é a que estabelece a posição que se assume perante um outro que nos interpela. A Sam, ativista pela causa negra, pode-se lhe interpelar tal qual mulher de periferia, solteira, ou que "namora um jovem branco", sendo esta capacidade da ação perante o mecanismo de interpelação que se trate o que vai sugerir ativar uma "posição de sujeito" específica. É desta maneira como o binarismo conceitual clássico se deslegitima, por força da própria complexidade nas relações sociais cotidianas.

Por isso, embora se apresente como meio de libertar os oprimidos, o construto da diferença dicotômica por oposição,

(...) pode resultar em efeito contrário. Ao não perceber a possível complementariedade na diferença entre os lados da dicotomia, a diferença de oposição dicotômica invariavelmente implica relações de superioridade e inferioridade, relações hierárquicas que se enredam com economias políticas de dominação e subordinação (Collins, 2016: 109).

Conforme Collins (2015), as identidades sempre serão produzidas por meio de experiências específicas de raça, classe e gênero, de modo que essas categorias não se apresentam excludentes, mas complementares. O pensamento com base em dicotomias só admite pontos fixos de identificação, como oprimido ou opressor, sentença que não parece ocultar uma leitura meramente estruturalista do mundo social. Se, contrariamente, a opressão social é, antes de tudo, um tipo de relação social (e não mais do que isto), chega-se a considerar, junto com Collins, que toda análise da opressão e exclusão social crítica deve admitir a existência concreta do "opressor que está plantado profundamente em cada um de nós" (Collins, 2015: 17). Dependendo do tipo de relação em questão, um indivíduo pode se localizar em situação de opressor, e em outra, em situação de oprimido.

Desse modo, por exemplo, mulheres estarão sempre em "posição inferior" perante os homens, ocupando o lugar, exclusivo, de oprimidas. Porém, considerando, também, a raça e a classe como componentes de identificação cultural, e tratando-se de uma "mulher branca" de classe média, esta pode, em determinada situação, ser a opressora de uma "mulher negra" pobre. A opressão que essa sofre enquanto mulher branca não seria anulada, entretanto, o que se observa é que os marcadores que constituem sua identidade formam diferentes arranjos de opressão. Em ambos os casos, há o atravessamento de componentes raciais, 
de classe e de gênero enquanto categorias interconectadas, produzindo relações e opressões distintas. Além disso, valorizando a "autodefinição das pessoas", Collins (2015: 17) atenta para o fato de que, apesar da "natureza imbricada das opressões", estas podem ser lidas e valoradas em níveis distintos pelas pessoas que as vivem.

Esse reconhecimento de que uma categoria pode ter primazia sobre outras por determinado tempo e lugar não minimiza a importância teórica de supor que raça, classe e gênero são categorias de análise que estruturam todas as relações (Collins, 2015: 19).

A leitura intersecional das múltiplas opressões que atravessam um mesmo sujeito poderia explicar as relações de dominação e subordinação - como se estruturam, como se mantêm e como são moldadas pelo arranjo dos sistemas de opressão de raça, classe e gênero. Com tais provocações, Collins (2015; 2016; 2017) visa não só a avançar no campo das análises acadêmicas, mas também no campo estritamente político, entendido, também estes, como imbricados. Collins traz, então, a ideia de intersecção do pensamento feminista negro norte americano que analisa e denuncia a natureza interligada da opressão. Esse tipo de análise por parte de mulheres negras ocorre justamente por conta de suas experiências que intersectam diferentes sistemas de opressão. Dessa forma, mulheres negras

seriam as primeiras a perceberem que minimizar uma forma de opressão, apesar de essencial, ainda pode deixá-las oprimidas de outras formas desumanizadoras. (Collins, 2016: 107).

Diferente de feministas brancas, por exemplo, feministas negras não entenderiam que homens negros sejam seus inimigos diretos, por compartilharem experiências de opressão ligadas à raça - como a segregação socioespacial nos Estados Unidos, marcadamente racista e classista. Entretanto, diferentes dos homens negros, estas não podem jogar a carta duvidosa da masculinidade com o objetivo de neutralizar o estigma de ser negro. Assim, as experiências vividas por mulheres negras ocorrem na intersecção entre as opressões raça, classe e gênero, possibilitando-lhe análises acerca da natureza e a estrutura das relações de dominação na economia política nos Estados Unidos.

A atenção dispensada por feministas negras à natureza interligada da opressão é significante por duas razões. Em primeiro lugar, esse ponto de vista muda todo o foco da investigação, partindo de uma abordagem que tinha como 
objetivo explicar os elementos de raça, gênero ou opressão de classe, para outra que pretende determinar quais são os elos entre esses sistemas. A primeira abordagem prioriza comumente um tipo de opressão como sendo primária e, em seguida, trata de opressões restantes como variáveis que fazem parte do sistema que é visto como o mais importante. (Collins, 2016: 108)

O olhar interseccional, então, é inicialmente utilizado por feministas negras que colocam em pauta as diferentes opressões que sofrem. Paulatinamente, este olhar ganhará espaço no campo acadêmico, sendo utilizado, justamente, por intelectuais ativistas negras. O primeiro registro é da jurista Kimberly Crenshaw, que, conforme Collins (2017), inspirou-se em escritos e registros de feministas negras para desenvolver suas análises, tendo a busca por justiça social como objetivo. Conforme Piscitelli (2006: 267), na abordagem de Kimberly Crenshaw, as interseccionalidades são consideradas como

formas de capturar as consequências da interação entre duas ou mais formas de subordinação: sexismo, racismo, patriarcalismo. Essa noção de "interação" entre formas de subordinação possibilitaria superar a noção de superposição de opressões. Por exemplo, a ideia de que uma mulher negra é duplamente oprimida, à opressão por ser mulher deve ser adicionada a opressão por ser negra. A interseccionalidade trataria da forma como ações e políticas específicas geram opressões que fluem ao longo de tais eixos, confluindo e, nessas confluências constituiriam aspectos ativos do desempoderamento.

Com base em uma perspectiva construcionista, com a qual Patricia Hill Collins parece coadunar, Avtar Brah (2006) analisa as problemáticas da "diferença” por meio da articulação de diferentes sistemas de opressão e dos discursos produzidos sobre estes. Nesse sentido, questiona categorias que visam a universalizar opressões e modos de resistência, como patriarcado e sisterhood. Segundo a autora,

nosso gênero é constituído e representado de maneira diferente conforme nossa localização dentro das relações de poder. (Brah, 2006: 341)

Assim, desde um olhar que intersecta e articula sistemas de opressão, Brah se utiliza da noção de "relações patriarcais". A subordinação da categoria gênero à categoria de classe (desigualdade social) é, dessa forma, problematizada. Da mesma forma, questiona-se a centralidade de qualquer das categorias de análise posta como universal. 
Seria muito mais útil compreender como relações patriarcais se articulam com outras formas de relações sociais num contexto histórico determinado. Estruturas de classe, racismo e gênero e sexualidade não podem ser tratadas como "variáveis independentes" porque a opressão de cada uma está inscrita dentro da outra - é constituída e constitutiva dela (Brah, 2006: 351).

Após refletir e justificar a interseccionalidade como método de análise da constante relação entre raça, gênero e classe enquanto sistemas de opressão, Collins propõe o uso de três dimensões de opressão. Tratam-se das dimensões institucional, simbólica e individual, consideradas enquanto lugar em que raça, classe e gênero operam em conjunto. Dessa forma, a autora desenvolve modelos de aplicação da interseccionalidade como categoria de análise, demonstrando a formação dos arranjos de opressão formados em diferentes contextos sociais. $\mathrm{O}$ desenvolvimento de tais modelos e sua aplicabilidade aos objetivos da presente análise justificam o foco que segue a abordagem de Collins. A seguir, buscando realizar uma leitura interseccional do nosso objeto de análise, o Capítulo 1 da série "Cara Gente Branca", faremos uso destas três dimensões de opressão.

\section{A dimensão institucional de opressão: a Universidade Winchester}

Para análise interseccional dos sistemas de opressão de gênero, raça e classe na dimensão institucional, Collins (2015) propõe, como modelo, o uso do sistema escravista nos Estados Unidos. Segundo ela, a escravidão foi comumente pensada como um sistema de opressão de raça, e muito raramente vista na intersecção entre o âmbito racial e de classe. Não se teria pensado, por exemplo, na eventual intersecção da raça, da classe e do gênero como âmbitos interligados no sistema de opressão escravista. É que, de fato, os impactos da escravidão foram diferenciados entre as mulheres negras e os homens negros, homens e mulheres brancas trabalhadoras e homens e mulheres brancas da elite. Dessa forma, geraram opressões distintas conforme cada um desses grupos, sendo marcadamente mais grave a sofrida pelos escravos e escravas.

Collins (2015) se vale desse modelo para analisar o quanto as relações de opressão nos Estados Unidos na atualidade têm base nesse período da história. Nesse sentido, enquanto o homem branco de elite no período escravocrata é o senhor que vive do trabalho de homens negros e mulheres negras escravizadas, bem como de brancos da classe trabalhadora, no presente, os donos ou ocupantes de cargos de chefia (diretores, reitores) de universidades seriam os mesmos homens brancos sob um novo contexto. Enquanto espaço legitimado de produção de conhecimento, a universidade não faz mais do que reproduzir, então, 
traços das estruturas de poder do sistema escravista, marcando lugares específicos e funções sociais conforme operem os marcadores de raça, classe e gênero.

Valendo-nos, como metáfora, da proposta de Collins (2015) para a análise do contexto da Universidade Winchester, pode-se realizar algumas reflexões. Primeiramente, embora não se dê destaque à condição de classe dos estudantes, a universidade pode ser entendida enquanto um ambiente bastante elitista. Os variados obstáculos postos aos estudantes negros, e mesmo a aparente homogeneidade de classe entre os personagens, coloca em discussão se os estudantes pobres e da classe trabalhadora poderiam (ou não) estar ali. Resulta interessante perceber que o reitor da universidade, por exemplo, é um homem negro, um homem negro em posição de poder, como a série o apresenta, e que não só pode representar uma exceção à regra, mas sim a evidência do cruzamento entre os marcadores sociais que o constituem. Se, enquanto homem negro, o reitor poderia utilizar-se de sua masculinidade para neutralizar o estigma ligado à raça, compreende-se, assim, que ocupando a posição que ocupa passa a ser "atravessado" por um marcador de classe que o situa em um estrato eventualmente superior. No entanto, embora este marcador possa ter maior força para neutralizar aquele ligado ao de raça, a suspensão da festa de Halloween e a investigação que se segue após a sua realização por parte dele apontam para a existência de um olhar sensível quanto a um caso de racismo na universidade, nos limites da ação institucional.

A complexidade dos impactos de um homem negro ocupar uma posição de poder é notável também nas discussões que ocorrem entre os estudantes durante a reunião dos coletivos negros. Enquanto Troy, que é representante estudantil e filho do reitor da universidade, propõe que se busque alguma ação junto à universidade, Sam e outros estudantes não veem essa ação como positiva. Na interpretação de Sam, apesar de o reitor ser negro, o fato de estar em posição superior aos estudantes não pode ser negligenciado, já que não se trataria de uma figura entendida como um membro do grupo ou representante legítimo para a demanda.

Mesmo que a universidade, na ficção televisiva, traga um personagem negro ocupando um cargo de liderança política, e que a sua trajetória não seja explanada nesse primeiro capítulo, pensar a dimensão institucional da opressão em Winchester não se limita à sua atuação. As relações entre os estudantes, por exemplo, também trazem marcas dessa estrutura. $\mathrm{O}$ incidente da festa será determinante. Após uma série de estudantes utilizarem de "Black face" e outros adereços para "se fantasiar" de negros, a repercussão crítica que Sam dá aos fatos em seu programa de rádio seria duramente criticada por estudantes 
brancos. Primeiramente, o fato de Sam utilizar um meio de "expressão criativa" das opressões sofridas por ela e seus colegas negros e negras em si é causa de incômodo, especialmente pelo tom irônico e provocativo notável no nome do programa. Em meio a críticas, porém, aparece uma série de elogios por parte de estudantes negras e negros que se veem representados pelas "falas" de Sam no programa. Um exemplo marcante no primeiro episódio é de um estudante que liga para a rádio e ouve ao programa manifestando sentir como se estudasse em uma universidade diferente da dos alunos brancos (ainda que no mesmo campus), referindo-se ao incômodo destes com relação às críticas feitas à festa. A resposta de Sam é bastante crítica: "Eles estão muito ocupados se cumprimentando por ter nos deixado entrar".

Nota-se uma diferença significativa nos pontos de vista com relação à festa de Halloween, sua repercussão, e mesmo a experiência de viver a universidade conforme o marcador de raça. A cena que mostra reunião de coletivos de estudantes negros - e a existência mesmo desses coletivos - destaca essas diferenças. Nessa reunião, a pauta central é a festa e o que os coletivos farão a respeito, em sinal de contraponto; no entanto, curiosamente, a reunião acabaria tomando outros desdobramentos. O que chama a atenção nesse ponto é a formação dos coletivos como espaços de resistência na universidade. Somado à narrativa do estudante no programa de Sam, trata-se da denúncia da existência de duas universidades distintas, uma para os negros e outra para os brancos. A coesão de grupo, como todo coletivo, seria, também, bem ensaiada: os estudantes negros organizariam as "quartas-feiras do macarrão com queijo", cujo objetivo final seria assistir à novela "Defamation"6.

Fica claro que, embora seja garantido a jovens negras e jovens negros o direito de acessar à universidade, estes ocupam lugares distintos dos estudantes brancos. Entre estes, parecem se desenhar fronteiras simbólicas, aparentemente instransponíveis. Dessa forma, percebe-se, nesse ambiente, a reprodução do que Collins (2016) conceituou como "racismo interno". Collins se vale desse conceito para abordar o tratamento recebido por empregadas domésticas negras em famílias brancas, nas quais são consideradas "como se fossem da família". Em paralelo, pode-se considerar, então, que os estudantes negros em Winchester são "como se fossem estudantes", ou seja, que o que se entende com a sentença "como

6 A série "Defamation" é uma paródia da série "Scandal" ( $\mathrm{ABC}$ ), dirigida e protagonizada por mulheres negras (Shonda Rhimes e Kerry Washington, respectivamente). Entre os personagens de "Cara gente branca" que se reúnem para assistir à série semanalmente, este momento é descrito com o termo "guilt pleasure", ou seja, um "prazer pecaminoso". De certa forma, trata-se de momento de "intervalo" na militância diária, dedicado ao entretenimento coletivo. 
se fossem" traduzisse a ideia de que eles, de fato, "não chegam" a ser estudantes, questionando, assim, o suposto direito de acessar à universidade. $\mathrm{O}$ "racismo interno" funcionaria para manter a hierarquia entre as raças na sociedade, por meio da qual os brancos permanecem em lugar de superioridade enquanto incluem e controlam aos negros aos seus espaços de privilégios. Assim, se os estudantes negros têm o mesmo direito dos brancos de frequentarem a universidade, esse direito não se concretizaria da mesma maneira nos dois casos. A igualdade que seria alcançada por meio do direito cívico é ferida pelo "racismo interno".

As diferenças de experiências com relação ao marcador de gênero são notáveis também entre os estudantes negros. Troy, filho do reitor, por exemplo, tem um trânsito relativamente fácil entre os grupos de estudantes na universidade. $\mathrm{O}$ uso de adereços que remetem ao estereótipo negro não parece atrapalhar nas suas relações. Entre estudantes negras que compõem os coletivos estudantis, no entanto, nota-se que aquelas que têm, ou querem fazer, amigos brancos, optam por utilizar os cabelos alisados, mantendo uma postura menos assertiva com relação a casos de racismo na universidade. Mas, contrariamente, teriam problemas em conseguir estabelecer relações sociais fora desses espaços e grupos de identificação racial imediata. Em consequência, essas estudantes acabam por sofrer certa hostilidade dentro dos coletivos de estudantes negros, mostrando uma associação entre determinado uso do cabelo e componentes estéticos com o posicionamento político e militante. Após esse ponto, podemos observar a dimensão simbólica da opressão.

\section{A dimensão simbólica de opressão: imagens e estereótipos de raça, gênero e classe.}

A dimensão simbólica da opressão se refere à constante produção e reprodução de estereótipos que instituem lugares específicos conforme operem os marcadores sociais de raça, gênero e classe. Por exemplo, as mulheres estariam associadas à imagem de "doçura" e "passividade" nas condutas e atitudes, enquanto os homens estariam associados a uma imagem oposta. Contudo, quando se observam os estereótipos produzidos em torno de mulheres negras, "doçura" e "passividade" são caracterizações que parecem não fazer sentido. $O$ eventual poder dessas imagens, que conduzem a estereótipos, residiria no fato de parecerem "inofensivas", porém, permitem a manutenção intacta de uma série de mecanismos de opressão sutis. De modo quase invisível, essas imagens mantêm a função de controlar e, até, "desumanizar" aqueles indivíduos aos que se dirigem.

O pensamento feminista negro tem tido um importante papel na tarefa de questionar os estereótipos produzidos em torno das imagens criadas sobre as 
mulheres negras. Por meio de práticas de autodefinição e autoavaliação, mulheres negras têm escrito a sua própria história, questionando as imagens produzidas pelo sistema de opressão, que visava a controlar e a disciplinar o "corpo negro". O questionamento e crítica a imagens preconceituosas somam-se a uma autoavaliação que terminaria funcionando como um "exercício de prevenção" à produção e reprodução de novos estereótipos (Collins, 2016).

No entanto, é importante destacar que a dimensão simbólica da opressão torna-se uma questão problemática de combater, por tratar-se de um tipo de opressão invisível aos olhares cotidianos e, em muitas situações, considerada de menor importância, confundida com estilos de brincadeiras e jocosidades que não suporiam mostrar um sistema de opressão a priori existente. Entre os estudantes negros de Winchester engajados na militância antirracista, por exemplo, nota-se a reprodução de uma série de imagens estereotipadas que, produzidas para reafirmar positivamente suas identidades com relação ao marcador de raça, acabam substituindo-as por outras, não menos ofensivas. Exemplo marcante, exposto de forma irônica, é a cena, protagonizada por Sam, na qual se dirige, caminhando, para ir à universidade. Sozinha, caminhando, ouve em seu smartphone uma música pop, animada, não conectada, em certo sentido, com o gosto estético e musical esperado por uma ativista feminista negra radical. Assim, ao cruzar-se com um grupo de estudantes que a conhecem devido à sua militância, Sam, imediatamente, altera a música que está ouvindo, colocando uma música de Rap que fala sobre racismo e preconceito racial, "politicamente correta" para uma jovem militante negra, mudando, inclusive, a própria postura corporal e expressão. A forma como é apresentada a cena, a ação instantânea e um pouco incômoda de Sam em mudar a música, indicam que se trata de uma nova "caixa" na qual a estudante se vê presa, um novo estereótipo que precisa cumprir sem exceção: a de uma jovem estudante negra militante.

Algo semelhante ocorre quando ela mesma, a "militante negra Sam", começa a namorar um jovem colega branco. Primeiramente, pareceria se deslegitimar uma suposta imagem séria que construiu a força de radicalidade política e narrativa engajada, ao se envolver, emocionalmente, com outra pessoa. Certamente, $o$ aspecto emocional dos jovens pode ser interpretado como vulnerabilidade em outros aspectos, e Sam assim o pareceu compreender aos olhos dos seus colegas. Em segundo lugar, tratava-se de um envolvimento emocional com um jovem branco, o que levaria a contradizer muitos dos argumentos políticos na sua luta antirracista. Mas isto só era percebido aos olhos dos outros; para Sam, não havia contradição nenhuma. "A senhorita Black Power namora caras brancos", diria um colega. Olhares inquisidores dos outros colegas, presentes na sala 
em que os coletivos estavam reunidos para discutir encaminhamentos sobre 0 ocorrido na festa de Halloween. Coloca-se, em definitivo, um conflito racial e pessoal na vida de Sam que não teria planejado, mas que saberia que se poderia produzir em qualquer momento. Ao descrever sua relação com Gabe (seu namorado) a uma amiga, expondo o que mais lhe agrada da relação com ele, por exemplo, o fato de poder rir e fazer coisas "normais" (ou seja, referindo-se a um mundo exterior ao da militância universitária), demonstra quanto a necessidade de cumprir, cotidianamente, o papel de militante pode ser verdadeiramente exaustivo e tedioso, demandando vivenciar as "múltiplas realidades" nas quais estamos inseridos. Sam torna sobressalente, com este episódio, a heterogênea constituição do próprio espaço da negritude e da política antirracista coadjuvante, algo característico de ambientes urbanos de crescente diferenciação social, ao tornar mais diverso e amplo o repertório de símbolos e significados que os indivíduos podem incorporar no processo de identificação pessoal e elaboração dos seus projetos de vida (Gadea, 2013). No entanto, a sua amiga, com a sua reação e resposta, também se lembra de algo, de uma fase escrita por Sam em seu blog pessoal: "Não se apaixone pelo seu opressor", imediatamente lhe recordando que foi nos comentários a essa frase a maneira como se haviam conhecido. E Sam ficaria em silêncio.

Sam, certamente, era uma jovem mulher negra militante que experimentava, em seu cotidiano, aquilo que Thomas (2005 [1923]) denominou "lógicas situacionais". Situações vividas são advindas de repertórios históricos e culturais de construção de identificações diversas, e Sam estava inserida nesse complexo cenário. Por isso, o esforço posto em contrariar estereótipos associados a ela enquanto mulher negra acabaria, curiosamente, por gerar um novo estereótipo, pesado e difícil de ser mantido, principalmente por não lhe garantir a liberdade pessoal própria de escolhas individuais. Além disso, Sam teria chegado demasiado longe, quando adverte se colocar perante a questão do "colorismo" ao se autoafirmar como "mestiça", e não como negra, tal qual seria o esperado. Tratou-se, obviamente, de uma oportuna estratégia para defender seu sentimento por seu namorado Gabe, enquanto homem branco. A repercussão negativa sobre seu namoro com Gabe e a sua apreensão quando ele vai participar da "quarta-feira do macarrão com queijo" mostram a força que as fronteiras simbólicas adquirem no contexto em questão, gerando sofrimento também entre aqueles que se "protegem" no interior delas.

A presença de Gabe na "quarta-feira do macarrão com queijo" também permite pensar o entrelaçamento das noções de raça, de gênero e de classe com relação a homens brancos e negros. Estando em um espaço ao qual "não pertence", 
Gabe seria hostilizado pelos colegas e amigos de Sam, provocando incômodo com as expressões de Regie. Gabe o chamaria para uma briga, e Regie, em resposta, manifestar-se-ia ofendido, supondo que o convite à briga estaria revestido de um ato claramente racista, já que ele, como homem negro, só poderia se defender por meio da força física. Nesse caso, a imagem simbólica construída em torno de ideais de masculinidade atravessados pelo marcador de raça se expõem. Gabe deixa o espaço, abandonando o encontro, sendo seguido, rapidamente, por Sam. Ele reclama de ter se sentido deslocado naquele espaço, maltratado pelos amigos de Sam, incompreendido pelo sentimento que tinha por ela. Ela responderia lhe fazendo entender que é dessa mesma forma que todos os dias se sente na universidade, como se "não pertencesse" a esse lugar. Como homem branco, a sensação de não ser bem-vindo era uma experiência nova para Gabe. Gabe "se entenderia branco", embora já o fosse aos olhos de todos.

A repercussão que o programa "Cara Gente Branca" teria entre os demais estudantes da universidade também resulta representativo da dimensão simbólica da opressão. Ao expor, com seu programa de rádio, suas críticas à festa de Halloween e o racismo ali constatado, Sam, rapidamente, tornar-se-ia objeto de ataques e piadas. Pelos corredores da universidade, por exemplo, a revista de humor "Pastiche" espalharia cartazes com a imagem de seu rosto questionando "onde está a liberdade de expressão", em clara resposta aos cartazes que ela divulgaria com a seguinte pergunta: "onde está a cultura negra?". O fato de Sam ser o alvo principal dos ataques poderia ser, justamente, pelo caráter intempestivo que ela apresenta com seu estilo assertivo com relação a seus posicionamentos políticos, inclusive sem deixar esperar pelas reuniões dos coletivos negros e as decisões que ela assumiria. Claramente, isto também manifesta algo importante: o fato de Sam ser uma mulher negra que mostra tal postura e posição não deve ser negligenciado, na medida em que outros colegas homens de militância não iriam receber esse tipo de tratamento hostil. Sam era negra, mas também uma mulher.

Mas um dos principais desdobramentos da festa seria a confissão de Sam, em seu programa, de ter sido, justamente, a principal responsável pela festa. Após a sua suspensão pela universidade, Sam teria invadido o perfil da revista humorística no Facebook, reativando o evento na ideia de convertê-lo a um experimento sociológico. Experimento que se basearia no uso de imagens de pessoas negras e artefatos associados à estética destes como "fantasia de Halloween". O resultado seria o aparecimento de uma série de símbolos racistas, sem o devido questionamento ou reflexão por parte da maior parte dos estudantes brancos, bem como o uso da chamada "Black face", prática entre 
pessoas brancas que pintam seu rosto de marrom ou preto. Interessante recordar que essa prática tinha sido usada (e fortemente associada), por exemplo, em novelas para que atores brancos representassem personagens negros, na medida em que aos atores negros lhes estava vedada a presença nestes espaços da cultura.

\section{A dimensão individual da opressão: a experiência da escolha}

Esta dimensão da opressão aborda como as categorias de raça, classe e gênero terminam moldando as biografias individuais e as consequentes visões de mundo. Trata-se da dimensão da ação dos indivíduos frente às estruturas de opressão que desenham suas identidades nas próprias ações que tomam, a fim de contrariar tais estruturas e não pretender reproduzi-las com relação aos outros. Correndo o risco de agir segundo o "opressor que está plantado profundamente em cada um de nós", as ações individuais, especialmente aquelas que se comprometem com a justiça social, passam a ser um exercício de reflexão constante.

Os casos de reprodução dos estereótipos, ou de "reelaboração" de estereótipos, tem relação direta com essa questão. Por exemplo, durante a reunião entre os coletivos negros, a discussão entre as jovens sobre o uso ou não do cabelo alisado cabe a ambas as dimensões. Desconsiderando os motivos da escolha individual de Coco (Colandrea Conners), Sam utiliza a não autenticidade do seu cabelo alisado como algo que a tornaria menos militante. Com relação a suas próprias práticas, controladas pela imagem de militante que visa a reproduzir, Sam terminaria por internalizar a ação do próprio opressor, com relação a si mesma, e fundamentalmente com as suas colegas. Em sua crítica à colega, que tenta manter amizade com grupo de estudantes brancas "patricinhas", Sam prefere não considerar experiências de opressão pelas quais Coco teria passado, remetendo-se a questionar a imagem do seu cabelo liso. Coco, posteriormente, em capítulos seguintes da série, mostrará mais uma vez a cultura do "colorismo", lembrando que ela é uma mulher negra de pele mais escura que a própria Sam, o que a tornaria alvo mais fácil de situações de racismo e preconceito.

Tais ações por parte de Sam também refletem a reprodução de um modelo de ativismo tido como em absoluto flexível e dinâmico, mas que de fato se mostra rígido e poderosamente dogmático. O que se observa, entretanto, conforme Collins menciona (2015), é o quanto a consciência se termina moldando por meio de ações concretas, práticas e racionais, e não tanto por 
meio de reflexões abstratas, produzidas no calor de marcos ideológicos. Isto fica claro quando se observa que as ações das jovens participando dos coletivos negros na universidade, e colocando-se em "posição de contestação" aos espaços que lhes foram determinados enquanto mulheres negras, produzem diferentes formas de ativismo e consciência, conforme suas experiências individuais. Nesse sentido, fundamentalmente seria na dimensão individual que se percebe o poder do sistema de opressão de raça, gênero e classe. Por meio dela, nota-se o quanto desse sistema foi internalizado por aqueles que são seus alvos principais. A dimensão individual, então, coloca as ações dos indivíduos frente ao sistema de opressão e seus mecanismos de controle em questão:

Enquanto essas três estruturas [raça, gênero e classe] moldam uma estrutura de oportunidades, eu, enquanto indivíduo, sempre tenho que escolher aceitar as coisas como elas são ou tentar mudá-las. (Collins, 2015: 28).

A dimensão individual da opressão parece estar em sintonia com um processo de individualização e diferenciação social que estes jovens negros universitários protagonizam na tarefa por insurgir-se contra uma situação coletiva em que se encontram e, de alguma maneira, poderem desenvolver estratégias de distanciamento e de saída de uma situação adversa. Por exemplo, o cabelo alisado de Coco não se pode entender como surgido de uma atitude que teria internalizado os dispositivos de segregação e de racismo, "descaracterizando" a maneira de levar o cabelo uma jovem ativista e militante negra. Coco traz um exemplo do significado da experiência individual de "dualidade de contextos" em muitos jovens negros do seu tempo, com base em uma espécie de "jogo de reversão" das identificações sociais atribuídas como dados inegáveis da realidade: se o esperado era ver uma jovem negra militante com cabelo "afro", Coco fez um exercício de desconstrução muito interessante. Coco encarnou a atitude que procuraria desconstruir essas identificações (ativista negra, jovem e mulher) para transformá-las em um projeto de responsabilidade e autodeterminação, experiência social ancorada, paradoxalmente, na eventual existência de "marcos de referência" individuais. Por tal motivo, a dimensão individual da opressão em Collins (2015) parece associar-se com uma perspectiva sociológica que procura compreender os sentidos dessas atitudes que levam muitos daqueles jovens negros a elaborar e participar de "lógicas situacionais" que terminam repercutindo na própria percepção sobre uma pertença racial e social, sobre gênero e classe, que precederia a suas próprias experiências sociais. 


\section{Reflexão final}

Como obra de ficção, o primeiro capítulo da série "Cara Gente Branca" possibilita visualizar a intersecção entre as categorias raça, gênero e classe enquanto sistemas de opressão no ambiente universitário. Este foi o objetivo das reflexões que precederam. Especialmente pelo retrato irônico da realidade que descreve, e das diferentes formas de reação dos estudantes perante situações diversas, a série permite observar a pertinência das análises de Patrícia Hill Collins quando o assunto é a inter-relação de sistemas de opressão e a estrita relação da ação dos indivíduos em contextos diversos. Com isto, "Cara Gente Branca" oficiou como referência para poder compreender-se, de maneira concreta, as três dimensões da opressão por ela analisadas, possibilitando uma reflexão em que a diversidade de variáveis sobre temas ligados à opressão, ao racismo e ao preconceito é um indicador das complexas relações sociais que se nos apresentam e desafiam para a sua compreensão.

\section{Referências}

BRAH, Avtar. Diferença, diversidade, diferenciação. Cadernos Pagu, v. 26, jan.jun. de 2006, pp. 329-376.

CARA gente Branca - Crítica - $1^{\circ}$ Temporada. Observatório do Cinema, S.d. Disponível em: $<$ https://observatoriodocinema.bol.uol.com.br/artigos/2017/04/cara-gente-brancacritica-1a-temporada> Acesso em: 13/09/2019.

CARA Gente Branca. Direção: Justin Simien. Netflix, 2017. Disponível em: <https:// www.netflix.com/br/title/80095698>. Acesso em: 13 set. 2019.

COLLINS, Patrícia Hill. Aprendendo com a outsider within: a significação sociológica do pensamento feminista negro. Revista Sociedade e Estado. v. 31, n. 1, jan.-abr. 2016.

COLLINS, Patrícia Hill. Se perdeu na tradução? Feminismo negro, interseccionalidade e política emancipatória. Parágrafo. v. 5, n. 1 Jan.-Jun. 2017.

COLLINS, Patrícia Hills. Em direção a uma nova visão: raça, classe e gênero como categorias de análise e conexão. In: MORENO, Renata (org.) Reflexões e práticas de transformação feminista. São Paulo: SOF Sempre viva Organização Feminista, 2015, pp. 13-43.

GADEA, Carlos A. Negritude e Pós-africanidade. Crítica das relações raciais contemporâneas. Porto Alegre: Ed. Sulina, 2013.

HALL, Stuart. Quem precisa da identidade? In: Silva, Tomás Tadeu da. Identidade e Diferença. A perspectiva dos Estudos Culturais, Petrópolis, RJ: Vozes, 2000.

LACLAU, Ernesto; MOUFFE, Chantal. Hegemonía e estrategia socialista: hacia uma radicalización de la democracia: Madrid: Siglo XXI, 1987. 
PISCITELLI, Adriana. Interseccionalidades, categorias de articulação e experiências de migrantes brasileiras. Sociedade e Cultura, v. 11, n. 2, jul./dez. 2008.

THOMAS, William I. (2005, orig. 1923), "La definición de la situación”. In: Cuadernos de Información y comunicación, n. 10, s/l.

Recebido em: 22/01/2018 Aprovado em: 04/07/2019

\section{Como citar este artigo:}

GADEA, Carlos A. e ACOSTA, Suélen Pinheiro Freire. A luta pela identidade: uma análise de "Cara Gente Branca" por meio da noção de interseccionalidade de Patrícia Hill Collins. Contemporânea - Revista de Sociologia da UFSCar, v. 9, n. 2, maio agosto. 2019, pp. 545-562. 